\title{
Agência nas margens: revisitar o conceito de injustiça hermenêutica
}

\author{
Camila Lobo \\ UNIVERSIDADE NOVA DE LISBOA
}

\begin{abstract}
Miranda Fricker's account of what is involved in cases of hermeneutical injustice has been the object of a prominent strand of criticism charging her of neglecting alternative hermeneutical resources developed by non-dominant groups. In this article, I argue that the critique might be extended to consider cases in which, although alternative hermeneutical resources are not in place, marginalized subjects can still be said to resist dominant interpretations of their experiences. I briefly suggest that Fricker's failure to account for marginalized subjects' agency can be traced back to her attribution of hermeneutical injustice to a matter of prejudice and to her reliance on a neutral account of reason, which ought to be rejected by liberatory philosophical projects.
\end{abstract}

Keywords: epistemic injustice; feminism; social epistemology; philosophy of language.

\section{RESUMO}

O trabalho de Miranda Fricker sobre injustiça hermenêutica tem sido criticado em virtude da sua desatenção à existência de recursos hermenêuticos alternativos, desenvolvidos por grupos não-dominantes. Neste artigo, defendo que essa crítica pode ser desenvolvida no sentido de considerar casos em que, apesar de não existirem recursos hermenêuticos alternativos, os sujeitos marginalizados mantêm a capacidade de resistir a interpretações dominantes das suas experiências. Sugiro ainda que as limitações da abordagem original de Fricker se devem à sua atribuição de casos de injustiça hermenêutica a uma questão de preconceito, bem como à sua recetividade a uma conceção neutra de razão, que deve ser rejeitada por projetos filosóficos liberatórios.

Palavras-Chave: injustiça epistémica; feminismo; epistemologia social; filosofia da linguagem. 
Miranda Fricker define o conceito de injustiça hermenêutica como uma forma de injustiça epistémica que ocorre quando
uma área importante da experiência social de alguém [é]
obscurecida do entendimento coletivo devido a um precon-
ceito identitário estrutural no recurso hermenêutico coletivo

que, por sua vez, é resultado

de uma marginalização hermenêutica persistente e generalizada.

(Fricker 2007:154-155)

De acordo com Fricker, quando a experiência social de alguém é obscurecida do entendimento coletivo em virtude de o sujeito ser membro de um grupo marginalizado, os nossos recursos hermenêuticos coletivos apresentam 'uma lacuna no espaço onde deveria constar o nome de uma experiência social particular' (Fricker 2007:150). Apesar de não esclarecer esta definição em detalhe, quando se refere a recursos hermenêuticos coletivos, a autora parece ter em mente 'as ferramentas cognitivas elinguísticas (i.e., os conceitos e as palavras) que utilizamos para compreender o mundo e para comunicar sobre o mesmo' (Mason 2021:3). O objetivo de Fricker é, pois, examinar o modo como estas lacunas conceptuais elexicais reproduzem relações de desigualdade entre membros de grupos dominantes e não-dominantes ao tornar os sujeitos marginalizados incapazes de compreender uma parte significativa das suas experiências sociais.

Uma preocupação e crítica recorrente ao tratamento que Fricker faz do conceito de injustiça hermenêutica tem a ver com a ideia, central à sua tese, segundo a qual estas lacunas nos recursos hermenêuticos coletivos impedem os membros de grupos marginalizados de fazer sentido das suas experiências. De facto, as descrições de Fricker sobre o modo como casos de injustiça hermenêutica confinam os sujeitos marginalizados a uma situação de 'escuridão epistémica' (Fricker 2007:149), que resulta numa 'desvantagem cognitiva' (Fricker 2007:151), parecem indicar uma tendência para desconsiderar a 
agência cognitiva destes sujeitos. Ao ignorar a possibilidade de que as pessoas marginalizadas possam, não obstante viverem sob sistemas opressivos, compreender as suas experiências, Fricker negligencia 'as práticas de resistência, epistémicas e comunicativas, de sujeitos não-dominantes e, ao fazê-lo, pode contribuir para a sua marginalização e desempoderamento' (Mason 2011:294). Num caso particularmente proeminente desta linha crítica, a autora é acusada de equiparar o conceito de recursos hermenêuticos coletivos à ideia de recursos hermenêuticos dominantes, desconsiderando assim os recursos interpretativos disponíveis a sujeitos e comunidades marginalizadas. Ao representar estas lacunas nos recursos hermenêuticos como puramente coletivas, Fricker negligencia o modo como o (des) entendimento dominante das experiências de grupos marginalizados envolve uma exclusão ativa de discursos e interpretações resistentes'. Como afirma Kristie Dotson:

Tal pressuposto não toma em consideração epistemologias alternativas, contramitologias, e transcrições escondidas que existem em comunidades hermeneuticamente marginalizadas entre elas próprias. [...] As relações de poder que produzem populações hermeneuticamente marginalizadas nem sempre são também capazes de suprimir o conhecimento sobre experiências de opressão e marginalização nessas populações marginalizadas.

(Dotson 2012:31)

Várias comentadoras têm, por isso, defendido que o tipo específico de injustiça sofrido por membros de grupos marginalizados, cujos

\footnotetext{
1 Fricker reconhece, em trabalhos posteriores, que aquilo que entende ser o nosso recurso hermenêutico coletivo 'não esgotará certamente o campo de todos os conjuntos de significados sociais que são utilizados localmente por este ou por aquele grupo numa dada sociedade' (Fricker 2016:163). Ao fazê-lo, Fricker expande a sua conceção de 'recurso hermenêutico coletivo' para falar dos conceitos e das palavras que são partilhados por, e acessíveis a, praticamente toda a gente numa dada sociedade. Tal reconhecimento é, porém, incompatível com as suas análises sobre o modo como lacunas nos nossos recursos hermenêuticos coletivos podem causar 'uma desvantagem cognitiva aguda' em membros de grupos marginalizados (Fricker 2007:151).
} 
recursos interpretativos são negligenciados - ou, de outro modo, excluídos - pelos recursos dominantes, não entra no âmbito da conceção de injustiça hermenêutica apresentada por Fricker uma vez que, nestes casos, os sujeitos com uma maior desvantagem cognitiva não são os sujeitos marginalizados (Mason 2011; Pohlhaus 2012; Dotson 2012; Toole 2019). Pelo contrário, a marginalização resulta e é aqui, simultaneamente, resultado de um tipo de ignorância situada que afeta primeiramente os membros de grupos dominantes que negligenciam, ou rejeitam ativamente, os recursos dos marginalizados. Mas ainda que possuam um entendimento inteiramente adequado das suas experiências sociais, os membros de grupos marginalizados consideram frequentemente que as suas experiências são sistematicamente negligenciadas, ignoradas, ou distorcidas pelos recursos hermenêuticos dominantes ${ }^{2}$. Por este motivo, outras noções têm sido propostas para dar conta do tipo específico de injustiça a que membros de grupos marginalizados são sujeitos quando os seus recursos não são reconhecidos pelos grupos dominantes.

Gayle Pohlhaus (2012), por exemplo, apresenta a noção de ignorância hermenêutica deliberada para designar casos em que grupos não-dominantes resistem ativamente a uma situação de injustiça hermenêutica, desenvolvendo recursos que lhes permitem compreender as suas experiências, enquanto os sujeitos dominantes ignoram estes mesmos recursos. Analogamente ao que se passa em casos de ignorância branca (Mills 1997), a ignorância hermenêutica deliberada ocorre quando grupos dominantes se recusam 'a reconhecer e a adquirir as ferramentas necessárias ao conhecimento de partes inteiras do mundo' (Pohlhaus 2012:729). É possível afirmar, ainda, que a ignorância hermenêutica deliberada resulta numa injustiça contributiva, noção desenvolvida por Dotson para dar conta de uma forma particular de injustiça epistémica que ocorre quando a recusa em reconhecer e adquirir recursos hermenêuticos coletivos 'tolhe a capacidade de um sujeito de conhecimento contribuir para

2 Cf. Mason 2011:300. 
os recursos epistémicos partilhados numa dada comunidade epistémica por comprometer a sua agência epistémica' (Dotson 2012:32).

Ao contrário do que acontece nos casos de injustiça hermenêutica descritos por Fricker, em casos de ignorância hermenêutica deliberada e de injustiça contributiva, são os membros de grupos dominantes quem sofre uma desvantagem cognitiva, na medida em que se tornam incapazes de compreender as experiências sociais dos sujeitos marginalizados. Epitomando tal condição, podemos facilmente conceber uma situação em que sujeitos, de outro modo socialmente privilegiados, tentam dar conta das experiências de grupos marginalizados enquanto se recusam a reconhecer o seu privilégio ao negligenciar 'conceitos arduamente lapidados' (Pohlhaus 2012:722) tais como 'supremacia branca', 'cultura da violação' ou 'classismo'. Assim, ainda que de facto resultem de uma desigualdade estrutural, estas formas de injustiça epistémica são manifestamente agenciais e, por isso, culpáveis. Mais concretamente, elas são culpadas de prejudicar sujeitos marginalizados, não na sua capacidade de compreender as suas experiências, mas na sua capacidade de comunicar essas experiências junto de grupos dominantes (Toole 2019:611). Este é o tipo de problemas que ficam por tratar na abordagem de Fricker à questão da injustiça epistémica e, em particular, da injustiça hermenêutica. Como explica Dotson, ao

$$
\begin{aligned}
& \text { limitar o conceito de injustiça epistémica a permutações } \\
& \text { aceitáveis das formas que descreve, Fricker cria uma } \\
& \text { estrutura conceptual que, se levada a sério, serviria para } \\
& \text { excluir formas persistentes de injustiça epistémica. }
\end{aligned}
$$

(Dotson 2012:41)

Neste ponto, quero argumentar que tais exclusões não são simplesmente resultado de uma opção de Fricker de circunscrever o espaço da injustiça hermenêutica a casos que são epistemicamente não-culpáveis (Fricker 2013:50), mas antes uma consequência direta da sua restrição do espaço da injustiça epistémica a situações que decorrem de um 'preconceito identitário' (Fricker 2007:27). 
A negligência de Fricker de recursos hermenêuticos não-dominantes (ainda) não contradiz a sua descrição da injustiça hermenêutica como um tipo de injustiça que, para além de impedir que a experiência social dos sujeitos marginalizados seja coletivamente compreendida, também impossibilita que estes sujeitos possam compreender as suas próprias experiências. De facto, a possibilidade (negligenciada por Fricker) de existirem recursos hermenêuticos alternativos que oferecem resistência aos recursos dominantes, e que estes possam incluir conceitos capazes de dar conta das experiências sociais dos grupos marginalizados, não implica que a injustiça hermenêutica não possa afetar sujeitos que não são fluentes em tais recursos alternativos, nem nega a existência de casos em que os recursos relevantes não estão disponíveis tanto em contextos dominantes como não-dominantes. Mas esta linha crítica acerca do trabalho de Fricker não se limitou a acomodar novas formas de injustiça epistémica a uma estrutura conceptual previamente incompleta. Revelou, ademais, como no contexto de sistemas ideológicos, o preconceito não pode ser encarado meramente como a causa de práticas epistémicas nocivas, mas deve sobretudo ser encarado como uma das suas consequências. É neste sentido que, do mesmo modo que formas de ignorância hermenêutica deliberada e de injustiça contributiva não encaixam nos moldes definidos por Fricker, também casos incontroversos de injustiça hermenêutica serão afinal mais complexos do que originalmente sugerido pela autora.

Considero agora a discussão levada a cabo por Fricker de um caso paradigmático de injustiça hermenêutica que ocorria quando, antes de o termo 'assédio sexual' ter sido cunhado na década de 70, as mulheres sujeitas a este tipo de abuso se encontravam impedidas de compreender uma parte significativa das suas experiências (Fricker 2007:149-150). Era este o caso de Carmita Wood, funcionária de escritório na Universidade de Cornell que, depois de se ver sujeita a repetidas investidas sexuais por parte de um professor do departamento onde trabalhava, procurou o apoio de um grupo feminista, no qual lhe foi possível partilhar a sua experiência de abuso com outras mulheres. Foi então que, nascido dos esforços coletivos de mulheres que se juntavam para partilhar experiências de abuso semelhantes, 
o conceito de assédio sexual como atualmente o conhecemos foi pela primeira vez articulado. Fricker descreve este momento como um 'lampejo de iluminação' que permitiu preencher uma lacuna nos recursos hermenêuticos coletivos com um conceito que dava conta da experiência de assédio sexual, durante tanto tempo incompreendida (Fricker 2007:153). A escuridão hermenêutica que havia deixado as mulheres numa situação de profunda confusão e isolamento era finalmente levantada com sucesso (Fricker 2007:153). Fricker abstém-se, porém, de explicar a relação entre as experiências de angústia que estas mulheres enfrentavam isoladamente, a sua busca ativa de apoio junto de espaços seguros, e o eventual momento em que se cunhou o termo 'assédio sexual'.

Há, inegavelmente, algo de muito intuitivo acerca da utilização que Fricker faz da metáfora da 'lacuna coletiva' neste contexto. Ao contrário do que acontece em casos de injustiça contributiva, a injustiça que algumas mulheres sofriam antes do conceito de assédio sexual ter aparecido parece qualificar-se adequadamente como um caso de injustiça hermenêutica uma vez que o conceito estava ausente tanto dos recursos dominantes como dos não-dominantes. No entanto, como Rebecca Mason (2011) argumenta, não é claro que as mulheres envolvidas nas reuniões que levariam à articulação do termo 'assédio sexual' fossem de facto tão incapazes de compreender as suas experiências de abuso como Fricker sugere. Tomando o caso de Carmita Wood como exemplo, Mason mostra que o próprio facto de Wood ter procurado o apoio de um grupo feminista é prova de que ela era capaz de compreender a sua experiência como algo de nocivo ou degradante (Mason 2011:297). De facto, se é verdade que Wood e as outras mulheres que participavam nas reuniões podem 'não ter percebido a significância mais ampla da [sua] experiência - por exemplo, que infelizmente se tratava de um fenómeno generalizado e comum na vida de muitas mulheres', foi precisamente o seu entendimento do episódio como uma forma de abuso que 'estimulou o movimento de resistência que foi responsável pela nomeação do assédio sexual' (Mason 2011:297-298). Aquilo que dá a este caso a aparência de ter sido ultrapassado exclusivamente através desse processo de nomeação é o facto de Fricker utilizar a metáfora da lacuna para se referir 
simultaneamente a uma escassez conceptual e lexical. Um aspeto importante da reavaliação que Mason faz deste tipo de injustiça é que, ao clarificar que a conceção de recursos hermenêuticos coletivos adotada por Fricker envolve tanto ferramentas conceptuais como lexicais, é-lhe possível identificar duas condições necessárias para que algo configure um caso de injustiça hermenêutica. Escreve Mason:

Um sujeito, S, sofre injustiça hermenêutica só se

(i) S é incapaz de compreender a natureza e a significância normativa da sua experiência social $e$, ou

(ii) S é incapaz de descrever a natureza ou a significância normativa de $e$ de tal modo que a maior parte das pessoas possa compreender.

(Mason 2021:9)

Onde Fricker (con)funde recursos conceptuais e lexicais na categoria mais ampla de recursos hermenêticos, Mason mostra que um sujeito pode (ii) não ter a capacidade de articular publicamente a sua experiência mesmo que (i) a sua compreensão da experiência em questão não seja afetada. Esta clarificação permite-nos distinguir duas formas distintas de injustiça hermenêutica de modo a termos, por um lado, um tipo de injustiça especificamente conceptual e, por outro, um tipo de injustiça especificamente lexical. Com esta distinção em mente, é possível afirmar que as participantes nas reuniões que eventualmente levaram à criação do termo 'assédio sexual' estavam certamente impedidas de (ii) descrever a natureza ou a significância normativa da sua experiência de tal modo que a maior parte das pessoas pudesse compreender devido a uma lacuna nos recursos hermenêuticos coletivos. Esta lacuna, porém, não as impedia necessariamente de (i) compreender a natureza e a significância normativa da sua experiência, i.e., não as impedia de a conceptualizar como uma experiência nociva, talvez até injusta ${ }^{3}$.

3 Mason prefere falar das lacunas relevantes nos recursos hermenêuticos como uma 'deficiência' de modo a traçar uma distinção entre casos de injustiça hermenêutica que envolvem ‘falhas ao nível da posse conceptual' e casos que envolvem ‘falhas ao nível da 
Apesar de Mason permitir, deste modo, restituir agência cognitiva a alguns sujeitos marginalizados, a sua abordagem é amplamente omissa relativamente à condição de sujeitos que sofrem injustiça hermenêutica em virtude de (i) serem incapazes de compreender adequadamente a sua experiência social. De facto, é possível conceber casos que precedessem a criação do conceito de assédio sexual, em que algumas mulheres - por exemplo, mulheres que não contavam com o apoio de uma estrutura feminista - não compreendessem a natureza e a significância normativa da sua experiência social. Mas se esta falha de compreensão for concebida como uma total incapacidade de assimilar a experiência relevante, somos novamente chamados a explicar de que forma é possível ultrapassar este tipo de injustiça especificamente conceptual. Intuitivamente, porém, gostaríamos de dizer que é necessário que alguém tenha já uma ideia daquilo que está em falta nos recursos conceptuais para que possa chegar a falar de uma lacuna.

Considere-se agora o caso de Joana, uma jovem feminista que é membro de um coletivo feminista onde se organizam grupos de leitura. No decorrer de uma discussão sobre trabalho doméstico e de cuidados, uma das companheiras de Joana introduz o termo 'carga mental' e, com ele, um novo conceito que Joana recebe com entusiasmo. Trata-se, afinal, da melhor explicação que alguma vez ouvira acerca de uma queixa feita recorrentemente pela sua mãe ao longo da sua juventude. Empatizando com a experiência de desvalorização da sua mãe perante a falta de reconhecimento de todo o trabalho que dedicara à família, Joana decide introduzir o conceito em casa: carga mental, um termo que designa o trabalho invisível necessário à supervisão de todas as tarefas envolvidas no trabalho doméstico e de cuidados, e que tradicionalmente recai sobre as mulheres. Ao regressar ao grupo de leitura na semana seguinte, Joana relata com ternura a resposta da sua mãe ao novo conceito: 'agora sempre que a chateio, vocifera: Olha lá a minha carga mental!'. Na explicação intuitiva que Joana oferece

aplicação conceptual' (Mason 2021:15). Consequentemente, estes últimos casos não decorreriam de uma deficiência no recurso hermenêutico coletivo, mas em resultado de uma 'distorção' (Mason 2021:17). 
sobre o processo de aquisição - e rápida fluência - do termo 'carga mental' pela sua mãe, ela limitara-se a dar à mãe 'uma expressão para dizer aquilo que ela tinha em mente há muitos anos!'. Ao contrário daquilo que é sugerido por Fricker, a experiência de Joana e da sua mãe indica que a noção intuitiva de uma lacuna nos nossos recursos hermenêuticos coletivos deve necessariamente referir-se a uma ideia pré-existente do que é que está em falta. Ao mesmo tempo, parece exagerado pensar que a ideia que a mãe de Joana tinha em mente pudesse corresponder a qualquer compreensão sofisticada da natureza e da significância normativa do fenómeno - por exemplo, do seu papel na divisão sexual do trabalho.

Neste ponto, gostaria de clarificar que estou convencida de que o valor dos esforços coletivos para preencher lacunas nos nossos recursos hermenêuticos partilhados se estende para além de meras práticas de nomeação de experiências sociais, anteriormente sem nome. De facto, parece haver um sentido em que aquelas mulheres que partilhavam experiências semelhantes de abuso se tornavam capazes de conceptualizar as suas experiências de modo absolutamente distinto do que haviam feito antes. $\mathrm{O}$ exercício de identificação de padrões e consequências dos abusos que haviam sofrido introduzia-as, assim, a verdadeiras práticas de criação de conceitos que tornavam as suas experiências inteligíveis para si e para os outros. A prática de nomeação não seria senão o último estádio desse processo. Mas se podemos aceitar que a injustiça hermenêutica tem o poder de impedir sujeitos marginalizados de compreender a significância - nomeadamente, a significância política - das suas experiências sociais, parece altamente ininteligível que estas mulheres não tivessem qualquer tipo de entendimento sobre essas experiências. Se assim fosse, como poderiam elas chegar a tomar parte em práticas coletivas de criação de conceitos? $\mathrm{Ou}$, de outro modo, como poderiam chegar a reconhecer o conceito em falta se não tivessem já uma ideia do que faltava?

A resposta de Fricker a esta questão é, aparentemente, simples: a vitória destas mulheres sobre o silêncio a que haviam sido remetidas é resultado da sua capacidade excecional para, coletivamente, despertar 'recursos de significação social até então adormecidos' (Fricker 2007:148). Esta conceção de pensamento liberatório coaduna-se 
com a sua atribuição de casos de injustiça epistémica ehermenêutica a uma questão de preconceito, que conduz a uma imagem de virtude epistémica em que o objetivo final é, precisamente, a neutralização do preconceito (Fricker 2007:96). Ao sustentá-la, porém, Fricker recorre a uma conceção neutra de racionalidade que não pode deixar de negligenciar as perspetivas e interesses situados tanto dos grupos dominantes como dos grupos não-dominantes ${ }^{4}$. Por este motivo, o seu apelo à excecionalidade do pensamento liberatório é incapaz de dar conta do processo que levou estas mulheres em busca dos conceitos relevantes - processo esse que foi, necessariamente, iniciado apesar da presença de preconceitos vários nos recursos hermenêuticos dominantes.

Uma análise mais cuidadosa permite compreender que a própria organização das práticas coletivas de criação de conceitos dependia da possibilidade de que as participantes possuíssem já, à partida, algum tipo de conceptualização das suas experiências sociais. Não podendo tratar-se de ideias sofisticadas decorrentes de práticas de deliberação argumentativas, estas conceptualizações devem ser entendidas como estados afetivos que permitiram a estas mulheres sentir que as suas 'experiências incorporadas de assédio entravam em conflito com as más interpretações que circulavam nos discursos dominantes' (Mason 2011:297) ${ }^{5}$. O facto de Fricker negligenciar este processo parece, agora, ser resultado de uma abordagem sustentada numa imagem de racionalidade que fundamentalmente exclui toda a afetividade do seu domínio. Uma reavaliação de conceções tradicionais de racionalidade e de objetividade - do tipo que encontramos em projetos liberatórios tais como as chamadas standpoint theories - pode, por isso, criar novas possibilidades de investigação sobre o tópico da injustiça hermenêutica. Uma teoria que procure restaurar a agência de sujeitos oprimidos é, neste sentido, uma teoria

\footnotetext{
4 Veja-se Crary (2018) para uma poderosa crítica à conceção neutra de racionalidade implícita na abordagem original de Fricker ao tema da injustiça epistémica.

5 Ênfase minha. A expressão originalmente utilizada por Mason (2011) é embodied. Traduzo o conceito de embodiment por incorporação de modo a dar conta da sua aplicação numa tradição filosófica que procura restabelecer o estatuto fundamental da afetividade nas nossas práticas racionais e cognitivas.
} 


\section{comprometida com uma abordagem que, concebendo a racionalidade em termos não-neutros, nos permita observar o modo como quoti- dianamente partimos da nossa subjetividade para chegar a posturas sérias e veementes na esfera pública.}

\section{REFERÊNCIAS}

Dotson, K. (2012). 'A Cautionary Tale: On Limiting Epistemic Oppression'. Frontiers: A Journal of Women Studies, 33 (1), pp. 24-47.

Crary, A. (2018). 'The methodological is political: What's the matter with "analytic feminism"?'. Radical Philosophy, 2 (2). Disponível em: https://www.radicalphilosophy. com/article/the-methodological-is-political. [Acedido Janeiro 2021]

Fricker, M. (2007). Epistemic Injustice: Power and the Ethics of Knowing. Oxford: Oxford University Press.

Fricker, M. (2013). 'How is hermeneutical injustice related to 'white ignorance'?'. Social Epistemology Review and Reply Collective, 2 (8), pp. 49-53.

Fricker, M. (2016). 'Epistemic Injustice and the Preservation of Ignorance', in Peels R. e Blaauw M. (eds), The Epistemic Dimensions of Ignorance. Cambridge: Cambridge University Press, 160-177.

Mason, R. (2011). 'Two Kinds of Unknowing'. Hypatia, 26 (2), pp. 294-307.

Mason, R. (2021). [No Prelo]. 'Hermeneutical Injustice', in Khoo, J. e Sterken R.K. (eds), Routledge Handbook of Social and Political Philosophy of Language. Disponível em: https://www.remason.org/uploads/8/1/2/6/8126749/hermeneutical_injustice_penultimate.pdf. [Acedido Janeiro 2021]

Mills C. (1997). The Racial Contract. Ithaca, NY: Cornell University Press.

Pohlhaus, G. (2012). 'Relational Knowing and Epistemic Injustice: Toward a Theory of Willful Hermeneutical Ignorance'. Hypatia, 27 (4), pp. 715-735.

Toole, B. (2019). 'From Standpoint Epistemology to Epistemic Oppression'. Hypatia, 34 (4), pp. 598-618. 